Research Article

\title{
Measurement and Prediction: Coupling Coordination of Finance and Air Environment
}

\author{
Yuqing Geng $\mathbb{D}^{1}$ and Yiqin Tan $\mathbb{D}^{2}$ \\ ${ }^{1}$ School of Business, Shanghai Dianji University, Shanghai 201306, China \\ ${ }^{2}$ School of Law, Guizhou University, Guiyang 550025, China \\ Correspondence should be addressed to Yuqing Geng; gengyq@sdju.edu.cn and Yiqin Tan; gzutyq@163.com
}

Received 29 February 2020; Accepted 13 March 2020; Published 7 April 2020

Academic Editor: Maria Alessandra Ragusa

Copyright $\odot 2020$ Yuqing Geng and Yiqin Tan. This is an open access article distributed under the Creative Commons Attribution License, which permits unrestricted use, distribution, and reproduction in any medium, provided the original work is properly cited.

\begin{abstract}
This study finds that the comprehensive development degree (CDD) of the finance subsystem is less fluctuated than that of the air environment subsystem, and both subsystems share similarities in spatial distributions. The coupling coordination degrees (CCD) keep fluctuating with varied development directions and extents in different regions; besides, the eastern regions are higher than the western ones for the coupling coordination degrees. In the next years, the coordination degrees of the regions will have different tendencies: despite of the former fluctuation trends, regions in the coordination range will have upward trends, while those in the transition range will be likely to decline. The results are useful in proposing corresponding measures to promote the coordination development between finance and air environment.
\end{abstract}

\section{Introduction}

The finance industry has complicated interactions with the air environment, which has attracted widespread attentions [1-3]. Finance growth is related to the improvement of air environment [4]; a benign air environment is fundamental during the finance development process; therefore, by improving the air quality, the financial industry can be developed [5]. Besides, the attractive air environment contributes to the optimized geographical layout or distributions of the finance industry [6]. Furthermore, finance is also vulnerable to the poor air environment such as haze and fogs [7]. On the contrary, finance has significant impacts on the air environment. When finance is orderly concentrated and developed, it will help improve the quality of the air [8]; otherwise, it is likely to lead to air environmental problems such as air pollution and haze via various approaches or activities [9-14]. Therefore, it is significant to explore the mutual coordination mechanism of finance and air environment and find applicable approaches to achieve their growth with coordination.

This study firstly establishes an evaluation index of finance and air environment by analyzing their coupling coordination mechanism; secondly, it uses IEW-TOPSIS to analyze CDD and CCD between finance and air environment based on the coupling coordination degree model; and thirdly, it predicts the future CCD and proposes specific measures based on the grey prediction model. The study mainly wants to (1) discover and compare the development statuses of the finance and the air environment subsystems, respectively, in the Zone for the decade, (2) explore the CCD of the system, and (3) formulate policies for the future development of the finance and the air environment.

\section{Literature Review}

Finance is defined as economic activities including currency issuance, loans, deposits, exchange transactions, circulation of securities, trust, domestic and international currency payment, and settlement [15-17]. Air environment refers to the functions of the atmosphere that provides stable ecological services for human activities [18] and reflects the status of the ecological environment and the effects of human activities. Though finance and air environment share some of the same elements (such as the outcomes of human 
activities), they are naturally not the same thing as the finance is a kind of specific tertiary industry and the air environment is a kind of ecosystem [19].

2.1. Impact of Finance on Air Environment. The finance is highly related to the air environment; the finance has both negative and positive impacts on the air environment. For the aspect of the negative effects, financial activities have caused pressure and serious adverse effects on the air environment, such as deteriorating air quality and the air pollution caused by the lack of funds for environmental governance [20]. In addition, financial activities such as credit and financing have increased the scale of industrial productions which indirectly increase greenhouse gas emissions [21]. Finance activities change the approaches and scales of investments into the energy consumptions [22], and the investments into the traditional energy fields inevitably lead to climate changes and increase the burden on the air environment protection. Finance changes energy consumptions by expanding industrial productions and by adjusting industrial structures $[23,24]$, both of which clearly explain how finance affects the air environment $[25,26]$.

At the same time, some studies have demonstrated the benefits of finance to the air environment. Finance stimulates changes of the air environment in a positive way and has positive impacts on the air environment [6]. For example, financial institutions can provide financial services to the real economy enterprises who can manufacture waste gas treatment facilities so that the air pollution control can be better realized [27]. In addition, finance itself is considered as a green industry [28], which helps to optimize the industrial structure and update economic functions and which is more conducive to the air environment protection [29-31]. Regional examples centered on the financial centers (Shenzhen, Shanghai, etc.) show that as a new economic growth approach, finance can help the renewal of urban functions and protect the air environment $[32,33]$.

2.2. Impact of Air Environment on the Finance. Increasing research also finds that the air environment has positive and negative effects on finance. On the one hand, the poor air environment, which is not adapted to the finance development, has negative impacts on the local finance; it is proved that local governments and people are more likely to reduce enthusiasm for financial activities and decrease the willingness of financial investment in the air-polluted regions $[34,35]$. Furthermore, air environment problems lead to the disease spread and dissatisfaction of the financial practitioners, which decrease the competitiveness and attractiveness of the local finance industry [36]. Air environment-related problems undermine the vitality of financial activities and hinder the sustainable development of finance.

On the other hand, finance can be promoted and supported by the air environment enhancement. The basis for improving air environment is to strengthen the construction of the environment-related infrastructure, use cleaner energy, adopt air environmental protection technology, and optimize the industrial structure; such activities indirectly stimulate the development of the financial industry [20,37]. In addition, good images of the air environment help to attract financial participants, enhance the competitiveness of the local finance, and promote the rapid development of finance. What is more, regions with good air environment have strong finance, economic, and demographic appeals [38]. Various programs have been launched in different regions to increase the quality of air environment and finance competitiveness; regions with good air environment have become well-recognized financial centers [39]. For example, the air environment of Shenzhen has a strong appeal to finance, and now, Shenzhen has become one of the popular financial centers in China.

2.3. Coupling Coordination between Finance and Air Environment. Obviously, the mutual interactions between finance and air environment are complicated because they support and restrict each other [40]. Coupling coordination is an effective approach to analyze the mutual correlations of finance and air environment and reflect the whole financeair environment system's evolution tendency to be ordered and harmonious [41]. Currently, there are studies focusing on the coupling coordination of different industry sectors (such as tourism, international trade, and economic industries) with the air environment $[6,27,42]$; however, there is still a lot of work to discover the coordination interaction mechanism of finance and air environment because their coupling coordination relationship is important in both theory and practice. Besides, currently, the coupling coordination relationship between them lacks suitable coordination theoretical mechanisms and widely accepted indicators to accurately measure. In addition, current studies mainly select one individual sample as the research case so that the temporal and spatial comparisons among different regions are usually ignored. Therefore, a more in-depth research on the comparisons of coupling coordination between the two subsystems of finance and air environment among different regions needs to be conducted [28].

\section{Study Area}

The Zone is a national strategic zone in China, which is defined as an economic zone with global influences and a leading demonstration zone for ecological environment enhancement and society sustainable development. It includes 11 regions, namely, Anhui (ANH), Chongqing (CHO), Guizhou (GUI), Hubei (HUB), Hunan (HUN), Jiangsu (JIS), Jiangxi (JIX), Shanghai (SHA), Sichuan (SIC), Yunnan (YUN), and Zhejiang (ZHE). It is a representative in China as it covers over $40 \%$ of the GDP and $32 \%$ of the provincial regions in China. Besides, it is focusing on environmental governance and finance growth these years, and how these two subsystems interact with each other is one of the key issues for the sustainability of the Zone. Furthermore, there are great differences temporally and spatially among regions in the Zone so that the in-depth research of the Zone is a good reference for other places to enhance 
coordination development between finance and air environment.

\section{Materials and Methods}

4.1. Coupling Coordination Mechanism and Evaluation Index. It is obvious to find that the subsystem of finance has complex interactions with the subsystem of air environment. The finance supports better air governance and protection and at the same time, undermines the air environment through certain financial resource allocations or activities. Besides, a good air environment also supports the financial development with high quality and optimize financial industry structures, while the polluted air environment can restrict the future enhancement of finance competitiveness and attractiveness. Therefore, finance and air environment have correlation relationships, and they share the coupling coordination mechanism [43]. Finance and air environment are two subsystems, which together form the finance-air environment coupling coordination system. The detailed coordination mechanism of coupling is shown in Figure 1.

According to this mechanism, this study sets up the evaluation index to measure the coupling coordination interactions of the two subsystems. This paper firstly selects indicators for the two subsystems, respectively, based on previous studies $[6,20,27,28,44-51]$. Secondly, the paper screens the data with several principles: (1) the data should represent the key components of the subsystems of the finance and the air environment; (2) indicators should be simple and easy to understand in order to reduce multicollinearity; and (3) the data can be continuously obtained $[20,49]$. Thirdly, through tests of correlation coefficients and significance, key indicators are selected to better illustrate the coupling coordination interactions between them. Hence, the evaluation index is constructed, which consists of two subsystems, six aspects, and nineteen indicators (Table 1). The detailed explanations of the aspects and indicators of the two subsystems and the calculation equations of certain indicators are shown in Table 1.

For the finance subsystem $[6,27,44-47,49]$, the finance scale aspect measures the actual amount of this industry, represented by the number of employees in the financial industry, total deposits and loans of the year, and the added value of this industry. The second aspect is the finance structure, which represents the performance quality of the industry, including financial correlation rate, insurance depth, financial concentrations, and loan structures. The finance efficiency aspect measures whether the financial industry operates efficiently by evaluating the input and output ratios, including insurance density, insurance payout ratio, and deposit-loan ratio of financial institutions.

For the air environment subsystem, three aspects are formed $[20,28,47,48,50,51]$. The aspect of the air environment pressure mainly refers to the air pollution, including the emissions of the air pollutants, such as smoke and dust, nitrogen oxide, and Sulphur dioxide. Air environment status aspect demonstrates the evolution and situations of the air environment, which are represented by the number of days with good air and the concentrations of the air pollutants, such as nitrogen oxide, inhalable particles, and sulphur dioxide. The air environment response aspect demonstrates the activities of human beings to achieve benign air governance; there are two indicators: the financial investments in air governance and the treatment capacity of the waste gas.

4.2. Data Processing and Calculation of CDD. The data are mainly from the following yearbooks of China which guarantee the objectivity of the data: Environmental Statistical Yearbook, Finance Yearbook, Region Statistical Yearbook, and Statistical Yearbook.

(1) Normalize the data (use the first formula for the positive indicators and the second for the negative). $x_{i j}$ is the matrix $X$ of alternative $i$ and indicator $j$ among all the regions in the statistical decade. $x^{\prime}=$ $\left(x_{i j}^{\prime}\right)_{m \times n}$ is the normalized matrix range.

$$
\begin{aligned}
& x_{i j}^{\prime}=\frac{x_{i j}}{\sum_{i=1}^{n} x_{i j}}, \\
& x_{i j}^{\prime}=1-\frac{x_{i j}}{\sum_{i=1}^{n} x_{i j}} .
\end{aligned}
$$

(2) Calculate the weight $W_{j}$ :

$$
W_{j}=\frac{1-P_{j}}{n-\sum_{j=1}^{n} P_{j}}, \quad j=1,2, \ldots, n,
$$

where $\ln f_{i j}$ is to guarantee the significance and $f_{i j}=\left(1+x_{i j}^{\prime} / \sum_{i=1}^{m}\left(1+X_{i j}^{\prime}\right)\right) ; P_{j}$ is the information entropy of the range and $P_{j}=-\left(\sum_{i=1}^{m} f_{i j} \ln f_{i j}\right)$, $i=1,2, \ldots, m ; j=1,2, \ldots, n$.

(3) Calculate the ideal positive solution (PS) and the negative solution (NS):

$$
\begin{aligned}
\mathrm{PS} & =\left(\max _{1 \leq i \leq m} x_{i 1}, \max _{1 \leq i \leq m} x_{i 2}, \ldots, \max _{1 \leq i \leq m} x_{i n}\right), \\
\mathrm{NS} & =\left(\min _{1 \leq i \leq m} x_{i 1}, \min _{1 \leq i \leq m} x_{i 2}, \ldots, \min _{1 \leq i \leq m} x_{i n}\right) .
\end{aligned}
$$

(4) Calculate CDD:

$$
\begin{array}{r}
\mathrm{CDD}=\frac{\sqrt{\sum_{j=1}^{n} W_{j}\left(x_{i j}-\mathrm{NS}\right)^{2}}}{\sqrt{\sum_{j=1}^{n} W_{j}\left(x_{i j}-\mathrm{PS}\right)^{2}}+\sqrt{\sum_{j=1}^{n} W_{j}\left(x_{i j}-\mathrm{NS}\right)^{2}}}, \\
i=1,2, \ldots, m .
\end{array}
$$

(5) Establish the evaluation grade of CDD (Table 2).

\subsection{Calculation and Prediction of CCD}

(1) CDD (Fin) is the CDD of the finance; CDD (Air) is the CDD of the air environment; $\theta$ and $\rho$ are coefficients of the two subsystems, respectively, which demonstrate the subsystems' contributions to the 


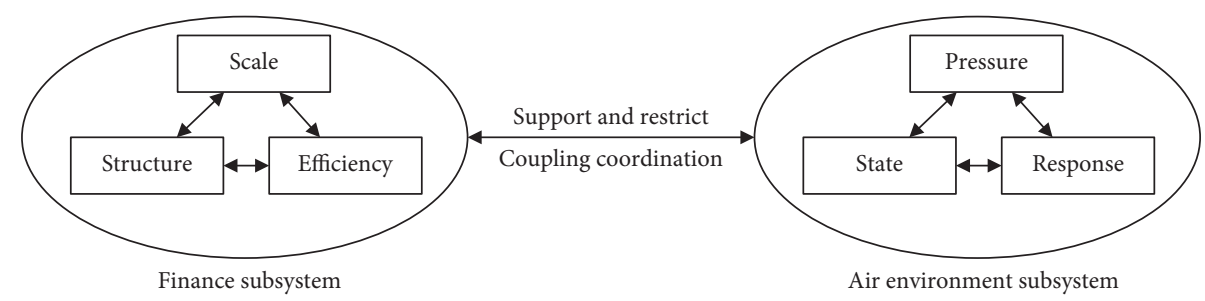

Figure 1: Coupling coordination mechanism.

TABLE 1: Evaluation index.

\begin{tabular}{|c|c|c|c|}
\hline Subsystem & Aspect & Evaluation indicator & Type \\
\hline \multirow{10}{*}{ Finance (Fin) } & \multirow{4}{*}{ Scale (Fin 1$)$} & Number of financial employees $\left(n_{1}\right)$ & Positive \\
\hline & & Total deposits and loans of the year $\left(n_{2}\right)$ & Positive \\
\hline & & Added value of the financial industry $\left(n_{3}\right)$ & Positive \\
\hline & & Financial correlation rate $\left(n_{4}\right)^{1}$ & Positive \\
\hline & \multirow{3}{*}{ Structure (Fin2) } & Insurance depth $\left(n_{5}\right)$ & Positive \\
\hline & & Financial concentrations $\left(n_{6}\right)$ & Positive \\
\hline & & Loan structures $\left(n_{7}\right)$ & Positive \\
\hline & \multirow{3}{*}{ Efficiency (Fin3) } & Insurance density $\left(n_{8}\right)$ & Positive \\
\hline & & Insurance payout ratio $\left(n_{9}\right)$ & Negative \\
\hline & & Deposit-loan ratio of financial institutions $\left(n_{10}\right)$ & Positive \\
\hline \multirow{9}{*}{ Air environment (Air) } & \multirow{3}{*}{ Pressure (Air1) } & Smoke and dust emissions $\left(p_{1}\right)$ & Negative \\
\hline & & Nitrogen oxide emissions $\left(p_{2}\right)$ & Negative \\
\hline & & Sulphur dioxide emissions $\left(p_{3}\right)$ & Negative \\
\hline & \multirow{4}{*}{ Status (Air2) } & Number of days with good air $\left(p_{4}\right)$ & Negative \\
\hline & & Nitrogen oxide concentrations $\left(p_{5}\right)$ & Negative \\
\hline & & Inhalable particle concentrations $\left(p_{6}\right)$ & Negative \\
\hline & & Sulphur dioxide concentrations $\left(p_{7}\right)$ & Positive \\
\hline & \multirow{2}{*}{ Response (Air3) } & Financial investments in air governance $\left(p_{8}\right)$ & Positive \\
\hline & & Treatment capability of the waste gas $\left(p_{9}\right)$ & Positive \\
\hline
\end{tabular}

${ }^{1}$ Calculation equations: financial correlation rate= total year-end finance deposits and loans/GDP; insurance depth=premium income/GDP; financial concentrations = (financial institutions' total deposits \& loans/added value of the tertiary industry)/(added value of the tertiary industry/GDP); loan structures = total long- and medium-term loans/loans from financial institutions; insurance density=premium income/number of the local population.

TABLE 2: Evaluation grade of CDD.

\begin{tabular}{lcccc}
\hline Value & CDD $<0.25$ & $0.25 \leq \mathrm{CDD}<0.50$ & $0.50 \leq \mathrm{CDD}<0.75$ & CDD $\geq 0.75$ \\
\hline Grade & Poor & General & Good & Excellent \\
\hline
\end{tabular}

finance-air environment system. As both subsystems are equally important in the contribution to the system, we hereby define $\theta=\rho=0.5$ [52]; calculate the system's CCD:

$$
\mathrm{CCD}=\sqrt{\left\{\frac{\mathrm{CDD}(\text { Fin }) \times \operatorname{CDD}(\text { Air })}{(\operatorname{CDD}(\text { Fin })+\operatorname{CDD}(\text { Air }) / 2)^{2}}\right\}^{1 / 2} \times\{\theta \operatorname{CDD}(\text { Fin })+\rho \operatorname{CDD}(\text { Air })\}}
$$

(2) Categorize CCD (Table 3).

(3) For the original time series $X_{0}=\left\{x_{0}(1), x_{0}(2), \ldots\right.$, $\left.x_{0}(n)\right\}$, accumulate the original sequence $x_{1}(t)=\sum_{i=1}^{t} x_{0}(i)$ to get a new sequence $X_{1}=\left\{x_{1}(1), x_{1}(2), \cdots x_{1}(n)\right\}$ ( $v$ : grey development value and $\varphi$ : grey endogenous control value).

$$
\varphi=\frac{\mathrm{d} x_{1}(t)}{\mathrm{d} t}+v x_{1}(t)
$$

(4) Calculate $\hat{a}=(v / \varphi)=\left(V^{T} V\right)^{-1} V^{T} B, \quad V=\left[-Z_{1}(2)\right.$, $\left.-Z_{1}(3), \ldots,-Z_{1}(n), 1,1, \ldots, 1\right]^{T}, \quad$ and $B=$ $\left[x_{0}(2), \ldots, x_{0}(n)\right]^{T}$; then, construct the prediction model: 
TABle 3: Category of CCD.

\begin{tabular}{lcc}
\hline Range & Category & Value \\
\hline \multirow{4}{*}{ Incoordination } & Highly incoordination & $0.000-0.199$ \\
& Moderately incoordination & $0.200-0.299$ \\
& Slight incoordination & $0.300-0.399$ \\
\hline \multirow{2}{*}{ Transition } & Approaching incoordination & $0.400-0.499$ \\
& Reluctant coordination & $0.500-0.599$ \\
\hline \multirow{2}{*}{ Coordination } & Primary coordination & $0.600-0.699$ \\
& Intermediate coordination & 0.700 to -0.799 \\
& High coordination & $0.800-1.000$ \\
\hline
\end{tabular}

$$
\widehat{x}(t+1)=\left[x_{0}(1)-\frac{\varphi}{v}\right] e^{-v t}+\frac{\varphi}{v}(t=1,2, \ldots, n) .
$$

To guarantee the prediction accuracy, $a$ should be less than 0.5, which is obtained from abundant practical experiences and now has been widely accepted as the principle of the accuracy test [53].

(5) Calculate the relative error $q(t)$ and the residual $p_{0}(t)$ :

$$
\begin{aligned}
q(t) & =\frac{p_{0}(t)}{x_{0}(t)} \times 100 \%, \\
p_{0}(t) & =x_{0}(t)-\widehat{x}_{0}(t) .
\end{aligned}
$$

(6) $\bar{x}_{0}=(1 / n-1) \sum_{t=2}^{n} x_{0}(t)$ and $\bar{p}_{0}=(1 / n-1) \sum_{t=2}^{n} \mathrm{p}_{0}(t)$ are the mean of $x_{0}(t)$ and $p_{0}(t) . S_{x}^{2}=(1 / n-$ 1) $\sum_{t=2}^{n}\left(x_{0}(t)-\bar{x}_{0}\right)^{2}$ and $S_{p}^{2}=(1 / n-1) \sum_{t=2}^{n}\left(p_{0}(t)-\right.$ $\left.\bar{p}_{0}\right)^{2}$ are the variance of $x_{0}(t)$ and $p_{0}(t)$. Calculate the variance ratio $C$ and the small error probability $P$. The model is accurate for prediction if $C \leq 0.8$ and $P \geq 0.6$ :

$$
\begin{aligned}
& C=\frac{S_{p}}{S_{x}} \\
& P=q\left(\left|p_{0}(t)-\bar{p}_{0}\right|<0.6745 S_{x}\right) .
\end{aligned}
$$

\section{Results and Discussion}

5.1. Discussion of CDD. Figure 2 and Table 4 show the temporal evolution of CDD for the finance subsystem in the Zone. In general, most regions are at the status of "general" (0.25 to 0.5$)$ and keep relatively gentle fluctuating. Among them, 11 regions' CDDs can be divided into 3 grades according to the temporal evolvement. (1) For the grade "good" (0.5 to 0.75$)$, there were three regions: Zhejiang, Jiangsu, and Shanghai. In detail, Jiangsu mildly increased whereas the rest two were both declining in CDD. Jiangsu's CDD rose from the grade "good" (0.5 to 0.75$)$ to "excellent" ( 0.75 to 1 ) from 2009 to 2018 mainly because Jiangsu had strong economic foundations and supporting policies to accelerate finance development. On the contrary, the decline of CDD in Zhejiang was quite obvious: it declined from 0.749 in 2011 (close to the grade "excellent" (0.75 to 1$)$ to 0.549 in 2018 (close to the grade "general"); this was mainly because the speed of Zhejiang's finance development was slower than that of the comprehensive economic growth. (2)
For the grade "general" ( 0.25 to 0.5$)$, there were 6 regions. Anhui, Hubei, and Sichuan maintained mild upward trends, whereas the CDDs in Yunnan, Hunan, and Chongqing were mildly declining; Yunnan witnessed a relatively obvious decline from the "general" grade (0.25 to 0.5) in 2009 to the "poor" grade (0 to 0.25 ) in 2018; thus, it is necessary to expand finance scale and promote financial growth. (3) For the grade "poor" (0 to 0.25 ), there were Jiangxi and Guizhou, who needed to implement relevant policies to support finance development and accelerate financial structure improvement.

Figure 3 and Table 5 show the temporal evolution of CDD for the air environment. It is clear to see that the air environment CDDs in the Zone are more fluctuated than those of the finance subsystem. The air environment CDDs can be divided into three grades. (1) The first grade "excellent" (0.75 to 1$)$ only included Anhui, which maintained a rapid growth with fluctuations: its CDD rose from the grade "poor" (0 to 0.25 ) in 2012 to the grade "excellent" (0.75 to 1$)$ in 2018 with relatively large fluctuations (obvious decreases in 2012 and 2015). The obvious leapfrog growth was mainly due to Anhui's increasing investment in air environment governance and upgrading of the industrial structures with sustainability, though such actions were not always continuous so that the CDD fluctuated. (2) The second grade "general" (0.25 to 0.5 ) included 9 regions. Most of them witnessed huge fluctuations: Yunnan and Jiangsu fluctuated between "general" ( 0.25 to 0.5$)$ and "excellent" (0.75 to 1$)$; Zhejiang and Hubei between "poor" (0 to 0.25$)$ and "good" ( 0.5 to 0.75). This was mainly because of the inequality of investments of air governance among the years. (3) The third grade is "poor" (0 to 0.25), including Chongqing only. It fluctuated between the grade "poor" and "general," and the lower CDD of it demonstrated that it should strengthen the construction of air treatment facilities and pay attention to improving the effectiveness of air environment governance.

The average grades of CDD for these two subsystems are shown in Figure 4 for spatial analysis. There is a similarity for the distributions of the CDDs. The eastern regions were higher than the rest regions for both subsystems. In detail, in the finance subsystem, due to the advantages of the foundation of the financial industry, economic development, population concentrations, etc., the CDDs in the eastern regions (Jiangsu, Shanghai, and Zhejiang) were much higher; on the contrary, due to the relative lower population attractiveness and financial development basics, middle and western regions had lower CDD, which was more apparent in Jiangxi and Guizhou. In the air environment subsystem, the situation is similar; the east had higher CDD (Jiangsu), while the west was lower (Chongqing). Such differences demonstrated the spatial inequality of air governance investments.

5.2. Discussion of CCD. Figure 5 and Table 6 show the temporal evolution of the CCD. In general, most regions kept the fluctuations, though the directions vary. (1) Anhui 


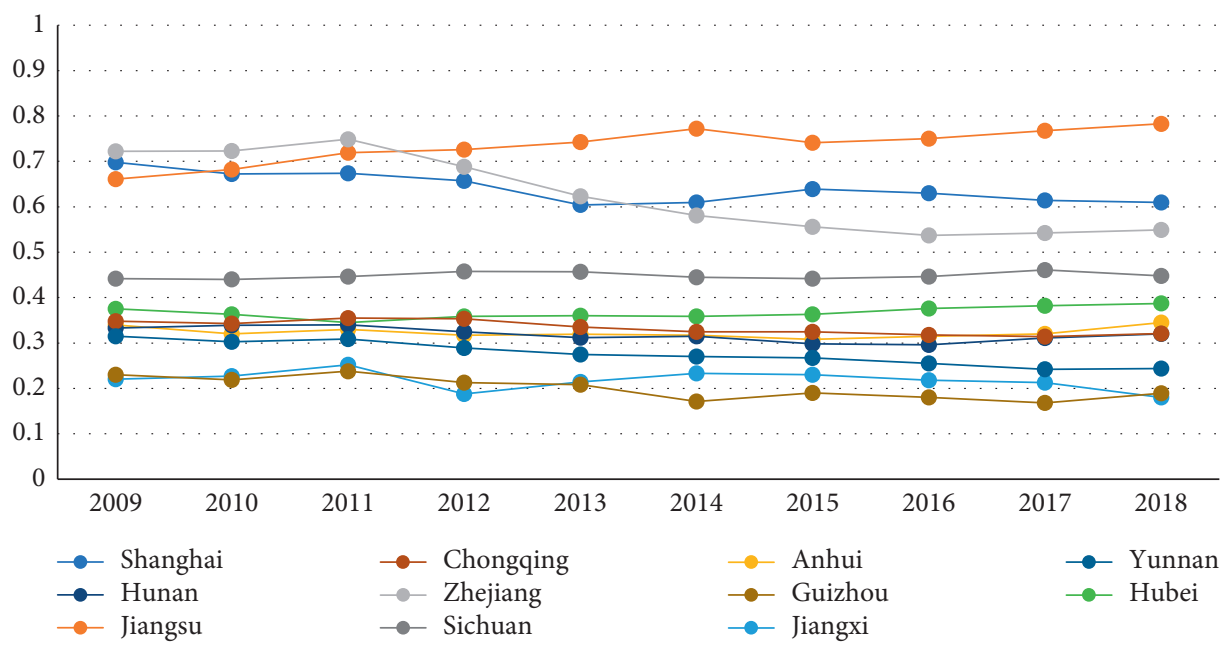

FIgURE 2: Temporal evolution of CDD for finance.

TABle 4: CDD of finance.

\begin{tabular}{lcccccccccccrr}
\hline & 2009 & 2010 & 2011 & 2012 & 2013 & 2014 & 2015 & 2016 & 2017 & 2018 & Average & Grade \\
\hline ANH & 0.340 & 0.320 & 0.330 & 0.317 & 0.319 & 0.317 & 0.308 & 0.315 & 0.320 & 0.345 & 0.323 & General \\
CHO & 0.348 & 0.343 & 0.355 & 0.353 & 0.335 & 0.325 & 0.325 & 0.318 & 0.314 & 0.321 & 0.334 & General \\
GUI & 0.230 & 0.219 & 0.238 & 0.213 & 0.208 & 0.171 & 0.190 & 0.180 & 0.168 & 0.189 & 0.201 & Poor \\
HUB & 0.375 & 0.363 & 0.345 & 0.359 & 0.360 & 0.359 & 0.363 & 0.376 & 0.382 & 0.387 & 0.367 & General \\
HUN & 0.333 & 0.339 & 0.340 & 0.325 & 0.312 & 0.315 & 0.298 & 0.296 & 0.311 & 0.320 & 0.319 & General \\
JIS & 0.661 & 0.682 & 0.719 & 0.726 & 0.743 & 0.772 & 0.741 & 0.750 & 0.768 & 0.783 & 0.735 & Good \\
JIX & 0.220 & 0.227 & 0.252 & 0.188 & 0.214 & 0.233 & 0.230 & 0.218 & 0.213 & 0.180 & 0.217 & Poor \\
SHA & 0.698 & 0.672 & 0.674 & 0.657 & 0.604 & 0.610 & 0.639 & 0.630 & 0.614 & 0.610 & 0.641 & Good \\
SIC & 0.442 & 0.440 & 0.446 & 0.458 & 0.457 & 0.445 & 0.442 & 0.446 & 0.461 & 0.448 & 0.448 & General \\
YUN & 0.315 & 0.303 & 0.309 & 0.289 & 0.275 & 0.270 & 0.267 & 0.255 & 0.242 & 0.244 & 0.277 & General \\
ZHE & 0.722 & 0.723 & 0.749 & 0.688 & 0.623 & 0.581 & 0.556 & 0.537 & 0.542 & 0.549 & 0.627 & Good \\
\hline
\end{tabular}

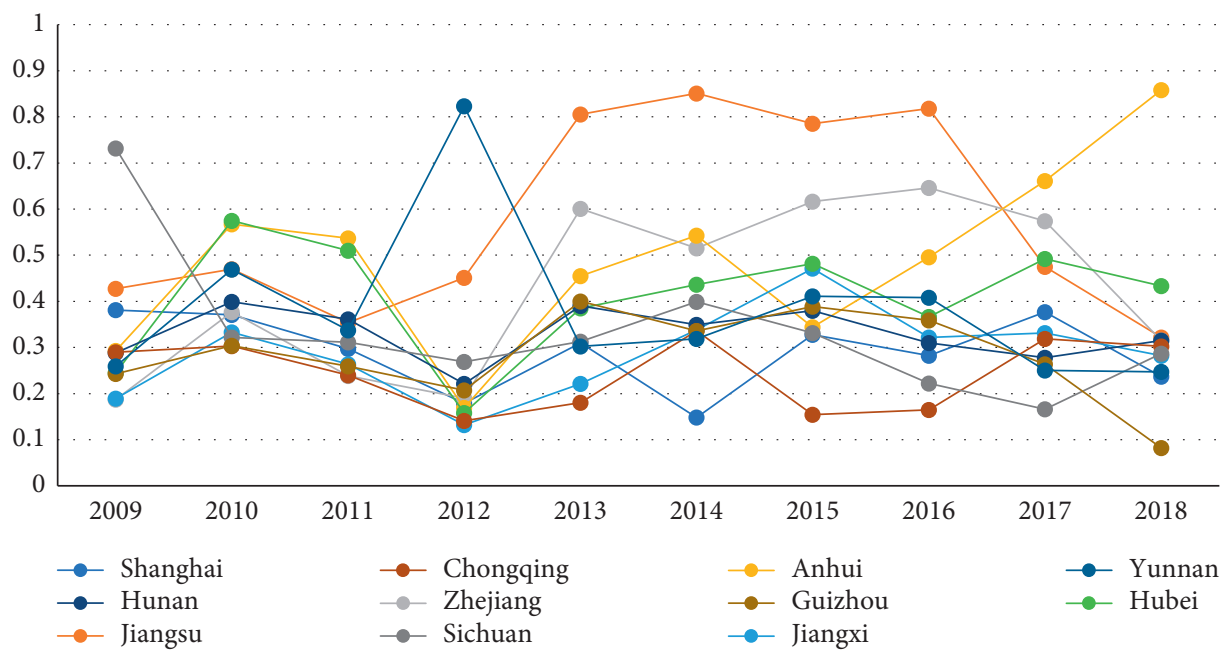

FIgURE 3: Temporal evolution of CDD for air environment.

had a delightful increase in CCD. It increased from reluctant coordination (0.5-0.6) in 2009 to intermediate coordination (0.7-0.8) in 2018 with relatively rapid growth, which was mainly due to the rapid improvement of its finance structure and scale and the improved air environmental response effectiveness. (2) Five regions faced decline within the different ranges with various fluctuation amplitudes. For instance, Shanghai mildly declined to the category of primary coordination (0.6-0.7) from the category of intermediate coordination (0.7-0.8), and Guizhou mildly dropped from the transition range $(0.4-0.6)$ to the incoordination range (0-0.4); compared with them, Jiangsu and 
TABLE 5: CDD of air environment.

\begin{tabular}{lccccccccccccc}
\hline & 2009 & 2010 & 2011 & 2012 & 2013 & 2014 & 2015 & 2016 & 2017 & 2018 & Average & Grade \\
\hline ANH & 0.293 & 0.567 & 0.537 & 0.169 & 0.455 & 0.543 & 0.344 & 0.496 & 0.661 & 0.858 & 0.492 & General \\
CHO & 0.290 & 0.303 & 0.240 & 0.141 & 0.180 & 0.336 & 0.154 & 0.165 & 0.319 & 0.302 & 0.243 & Poor \\
GUI & 0.243 & 0.304 & 0.259 & 0.207 & 0.400 & 0.336 & 0.389 & 0.359 & 0.264 & 0.082 & 0.284 & General \\
HUB & 0.245 & 0.575 & 0.501 & 0.158 & 0.385 & 0.436 & 0.482 & 0.366 & 0.492 & 0.433 & 0.408 & General \\
HUN & 0.288 & 0.399 & 0.361 & 0.221 & 0.390 & 0.349 & 0.380 & 0.310 & 0.278 & 0.315 & 0.329 & General \\
JIS & 0.427 & 0.470 & 0.354 & 0.451 & 0.805 & 0.851 & 0.785 & 0.818 & 0.475 & 0.322 & 0.576 & Good \\
JIX & 0.189 & 0.333 & 0.264 & 0.132 & 0.221 & 0.338 & 0.471 & 0.322 & 0.331 & 0.282 & 0.288 & General \\
SHA & 0.381 & 0.371 & 0.297 & 0.179 & 0.31 & 0.148 & 0.328 & 0.282 & 0.377 & 0.237 & 0.291 & General \\
SIC & 0.732 & 0.322 & 0.311 & 0.269 & 0.313 & 0.399 & 0.331 & 0.222 & 0.166 & 0.287 & 0.335 & General \\
YUN & 0.259 & 0.469 & 0.337 & 0.823 & 0.302 & 0.319 & 0.411 & 0.408 & 0.250 & 0.247 & 0.382 & General \\
ZHE & 0.187 & 0.377 & 0.238 & 0.190 & 0.601 & 0.515 & 0.616 & 0.646 & 0.574 & 0.315 & 0.426 & General \\
\hline
\end{tabular}
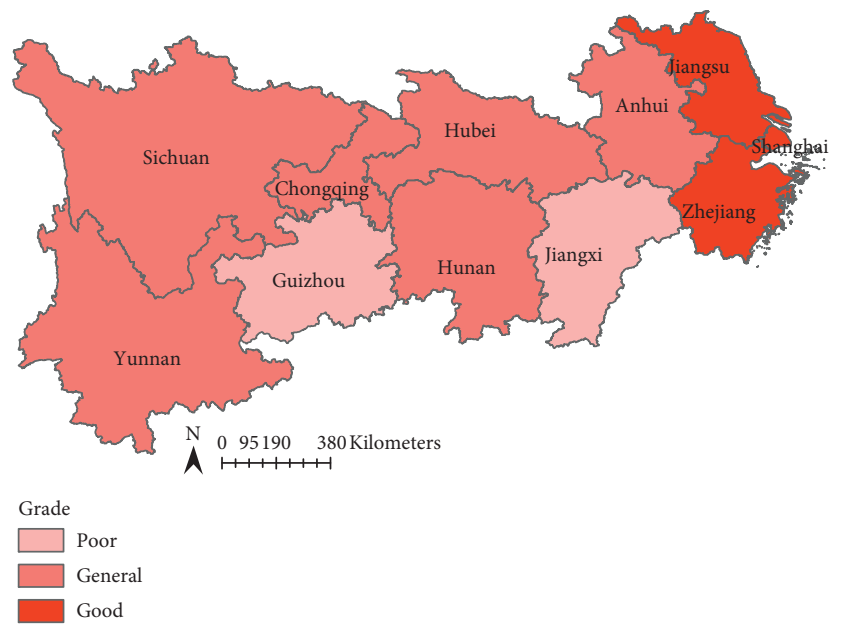
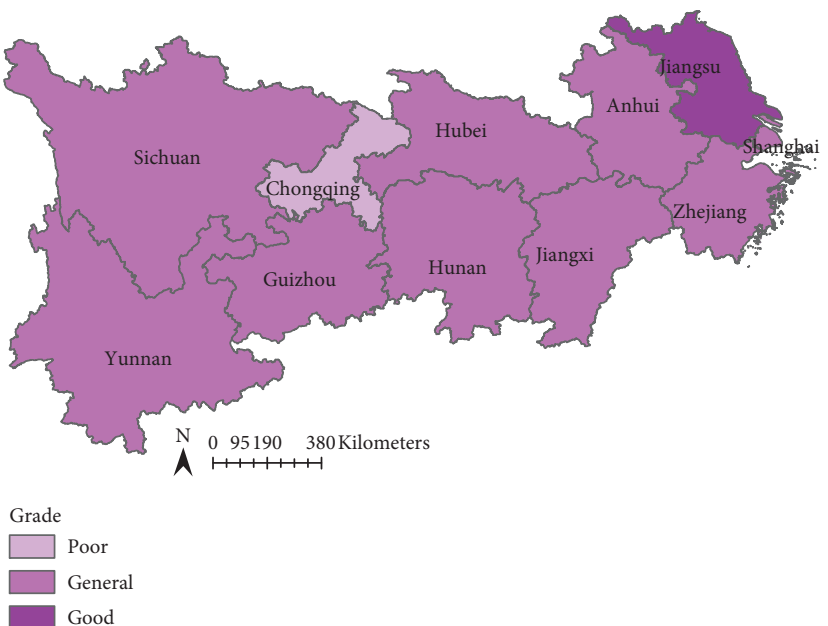

(a) (b)

Figure 4: Spatial distribution of CDD: (a) finance CDD; (b) air environment CDD.

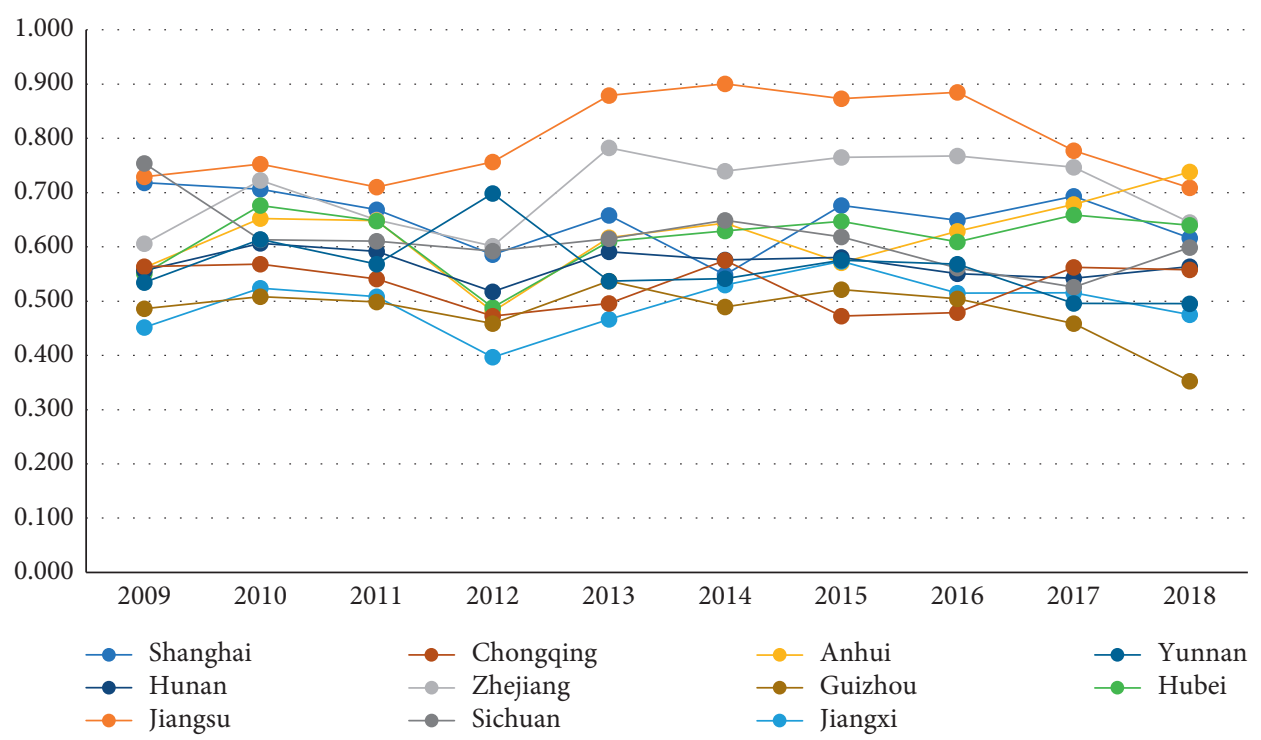

Figure 5: Temporal evolution of CCD.

Zhejiang had more drastic fluctuations. Though these regions had different statuses of finance-air environment coordination development; such declines demonstrated the less and less imbalanced coordination development between the two subsystems. (3) The rest 5 regions had mild fluctuations within the transition range, including Jiangxi, 
TABLE 6: CCD of the finance-air environment system.

\begin{tabular}{lllllllllll}
\hline & 2009 & 2010 & 2011 & 2012 & 2013 & 2014 & 2015 & 2016 & 2017 & 2018 \\
\hline ANH & 0.562 & 0.652 & 0.648 & 0.481 & 0.617 & 0.644 & 0.571 & 0.629 & 0.678 & 0.738 \\
CHO & 0.564 & 0.568 & 0.540 & 0.472 & 0.496 & 0.575 & 0.472 & 0.479 & 0.563 & 0.558 \\
GUI & 0.486 & 0.508 & 0.498 & 0.459 & 0.537 & 0.489 & 0.521 & 0.504 & 0.459 & 0.353 \\
HUB & 0.550 & 0.676 & 0.648 & 0.488 & 0.610 & 0.629 & 0.647 & 0.609 & 0.659 & 0.640 \\
HUN & 0.556 & 0.606 & 0.592 & 0.517 & 0.591 & 0.576 & 0.580 & 0.551 & 0.542 & 0.563 \\
JIS & 0.729 & 0.752 & 0.710 & 0.756 & 0.879 & 0.900 & 0.873 & 0.885 & 0.777 & 0.709 \\
JIX & 0.451 & 0.524 & 0.508 & 0.397 & 0.466 & 0.529 & 0.573 & 0.515 & 0.515 & 0.475 \\
SHA & 0.718 & 0.707 & 0.669 & 0.586 & 0.658 & 0.548 & 0.676 & 0.649 & 0.694 & 0.617 \\
SIC & 0.754 & 0.613 & 0.610 & 0.592 & 0.615 & 0.649 & 0.618 & 0.561 & 0.526 & 0.599 \\
YUN & 0.534 & 0.614 & 0.568 & 0.698 & 0.537 & 0.541 & 0.576 & 0.568 & 0.496 & 0.495 \\
ZHE & 0.606 & 0.723 & 0.650 & 0.601 & 0.782 & 0.740 & 0.765 & 0.767 & 0.747 & 0.645 \\
\hline
\end{tabular}

Hubei, Hunan, Chongqing, and Sichuan. Further actions were needed to enhance the coordination development between finance and air environment for these regions.

Figure 6 shows the spatial evolution of CCD. In general, the CCDs have spatial imbalances among and within different parts. There are two detailed findings. (1) The CCDs in the eastern regions (Shanghai, Jiangsu, and Zhejiang) were the highest, whereas those in the western regions (Sichuan, Chongqing, Guizhou, and Yunnan) were relatively lower. The three eastern regions were higher mainly because they had more advanced financial basis and efficiencies, complete industrial structures, competitiveness in attracting talents, and investment in air environmental governance, which guarantee the benign coordination between finance and air environment. On the contrary, the western regions were relatively lower in CCD mainly because of the weak finance scale and efficiency, the imbalanced financial structures, the fragile status of air environment, and the poor investment in air governance. Besides, in the middle part, these regions (Hubei, Hunan, and Jiangxi) perform average in CCD: worse than the east while better than the west. (2) The northern regions were higher than the southern regions in CCD. This is applicable for the eastern, middle, and western parts. For instance, Jiangsu in the eastern part, Hubei in the middle part, and Sichuan in the western part were higher in CCD than the southern regions within the corresponding parts, respectively. This was possibly because of the geographical advantages in the northern regions: there were more flatlands which were easier for the development of the financial industry.

5.3. Predictions of CCD. Table 7 shows the predictions of CCD in the Zone. The data passed the accuracy tests and can be used for further predictions.

The tendencies of the CCD will be different as in the past ten years. In general, the tendency will mainly be "making the strong stronger and the weak weaker": most regions in the coordination range will stop the decline tendencies and have benign trends, while those in the transition range will mostly face the tendency of decline. (1) For the regions in the coordination range, Jiangsu, Zhejiang, and Hubei will have the positive direction from decrease to increase, while Anhui and Shanghai will continue the former evolution patterns, though Anhui is upward whereas Shanghai is downward.
Among them, Jiangsu will grow from the intermediate coordination category $(0.7$ to 0.8$)$ to the high coordination category ( 0.8 to 1 ); Zhejiang will be promoted to the category of intermediate coordination ( 0.7 to 0.8$)$ from the category of primary coordination (0.6 to 0.7$)$. (2) For the regions in the transition range, most of them will decline in the value of CCD for the next three years. The only exception is Jiangxi which will have a little increase in CCD. Obviously, the decline of CCD is not a good sign for these regions, so relevant measures should be taken to prevent the CCD from declining.

\section{Measures}

For the regions in the Zone, the CCD of the finance-air environment system has significant differences temporally and spatially; therefore, sustainable finance growth and air environment governance are crucial to the integrated development of the Zone. Based on these, the following measures, which are also applicable for other regions with similar status for references, are specifically proposed in this study.

For the western regions where the CCDs are low with the declining trends, they need to do more to develop the finance industry and air environment governance so that the leapfrog coordination development between them can be achieved. (1) Learn from the advanced regions and copy the working methodologies with proper adjustments; for example, local governments can initiate talent-exchange programs, set up human resource training programs, and gain governors' skills and capabilities of governance in finance and air environment. (2) Make use of national supporting strategies to develop finance and air environment governance comprehensively, for example, the Belt and Road Initiative, the policy of environmental governance, and the strategy of the Yangtze River Economic Zone Development can be efficiently used to enhance the coordination development of the two subsystems for these regions.

For the eastern regions where the CCDs are high with the declining trends, efforts are needed to prevent further decline and to keep the CCD at the coordination status. There are certain specific countermeasures. (1) Innovate new approaches to promote financial growth, for instance, initiate new talent introduction programs to increase the attractiveness for financial talents by highlighting improving air 

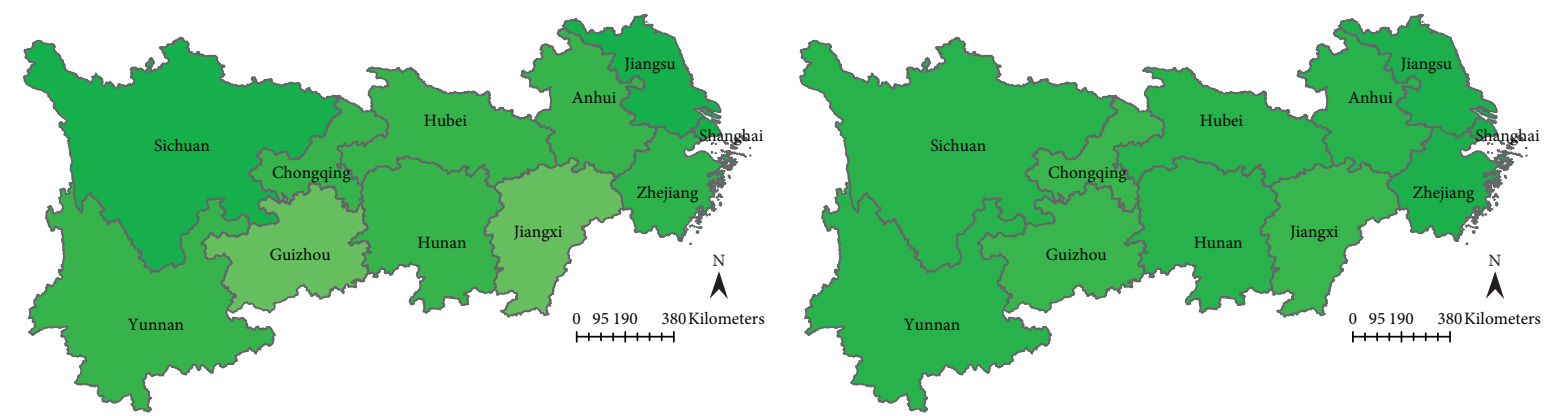

Category

Approaching incoordination

Reluctant coordination

Primary coordination

(a)

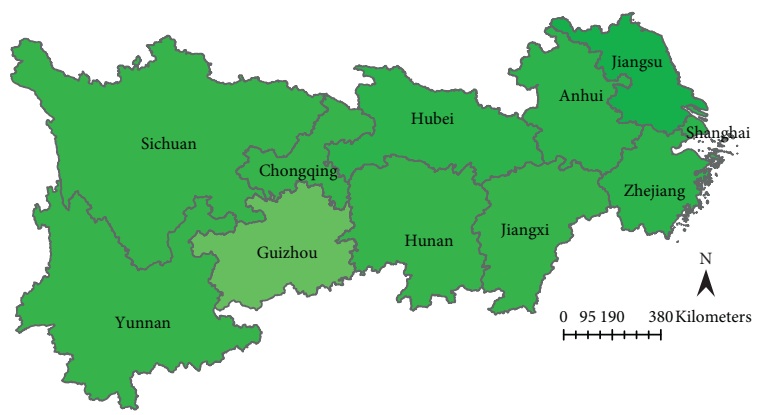

Category

$\square$ Approaching incoordination

Reluctant coordination

Primary coordination

Intermediate coordination

(c)

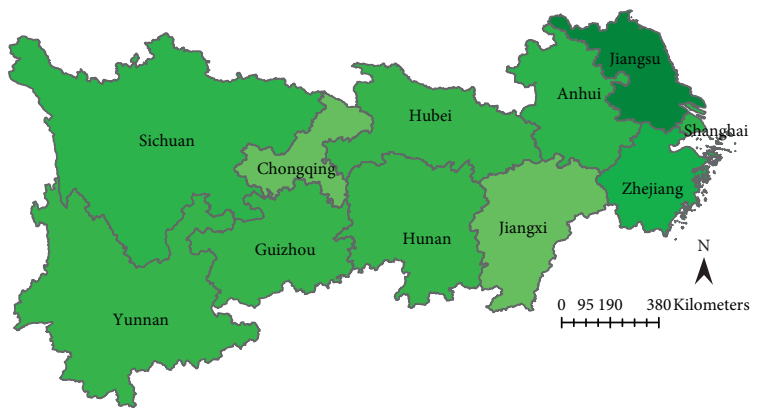

Category

$\square$ Approaching incoordination
Reluctant coordination

Intermediate coordination

Reluctant coordinatio

(e)

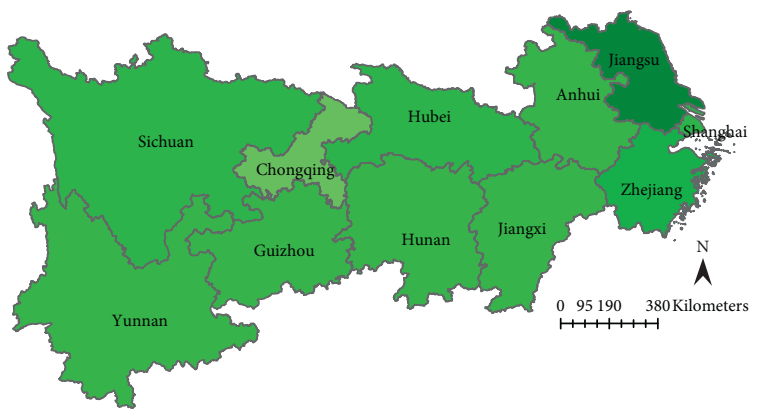

Category

Approaching incoordination

Reluctant coordination

Primary coordination
Intermediate coordination

High coordination
Category
$\square$ Reluctant coordination
$\square$ Primary coordination

(b)

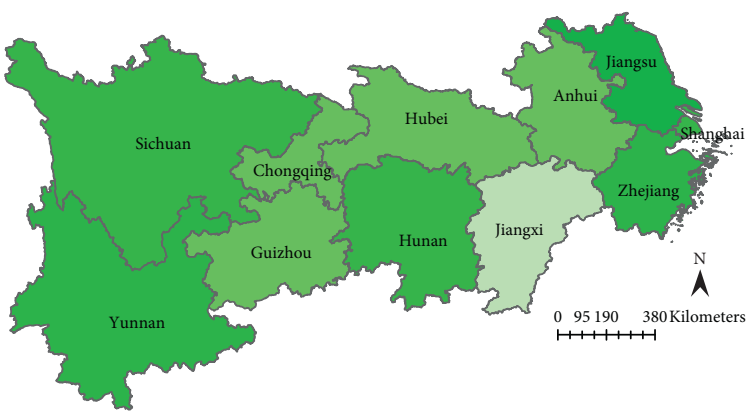

Category

$\square$ Slight incoordination
$\square$ Approaching incoordination
Reluctant coordination

Primary coordination

(d)
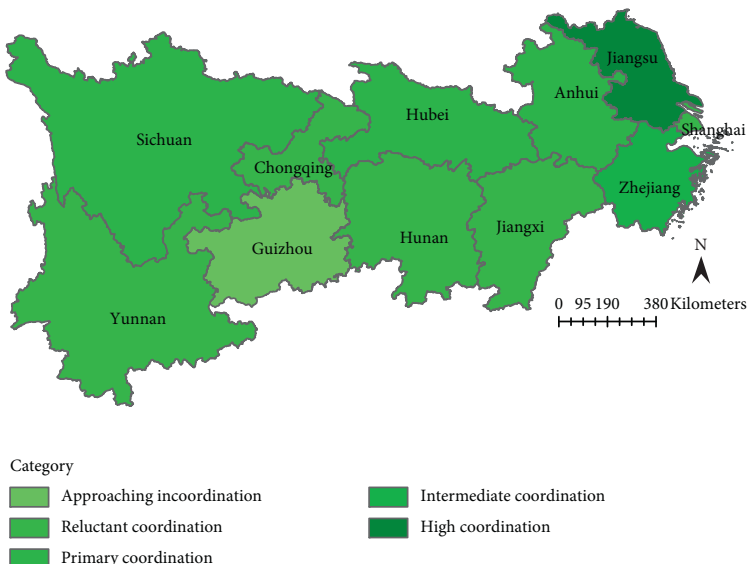

(f)
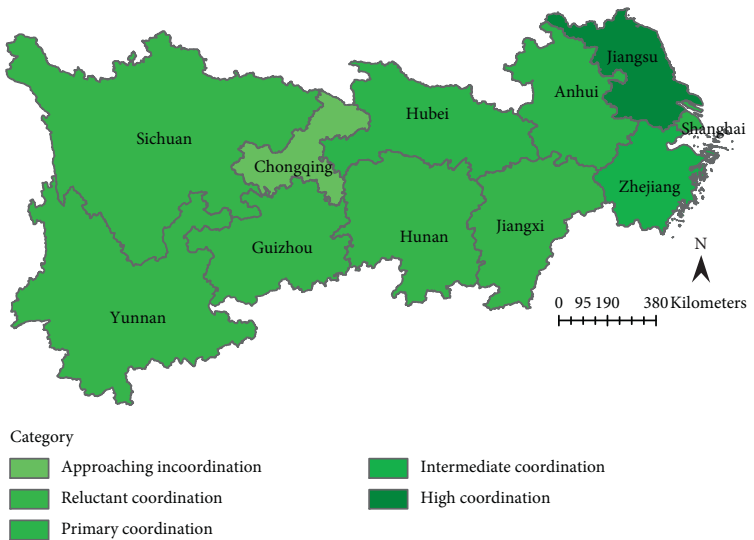

Intermediate coordination

High coordination

FIgURE 6: Continued. 


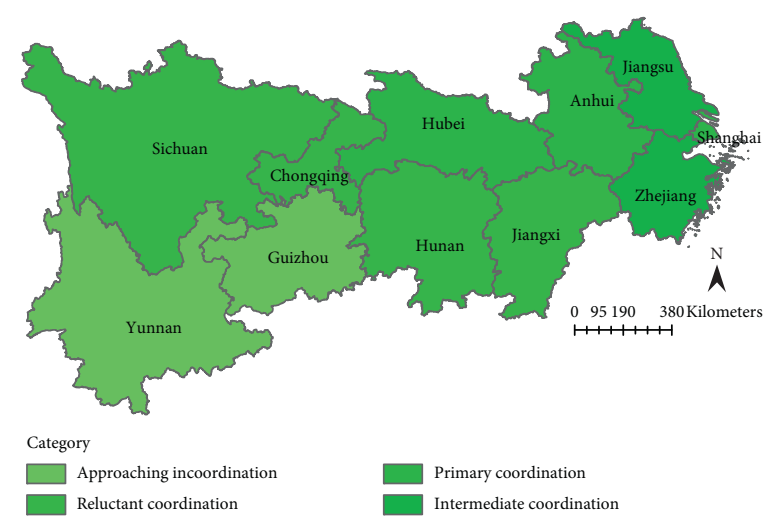

(i)

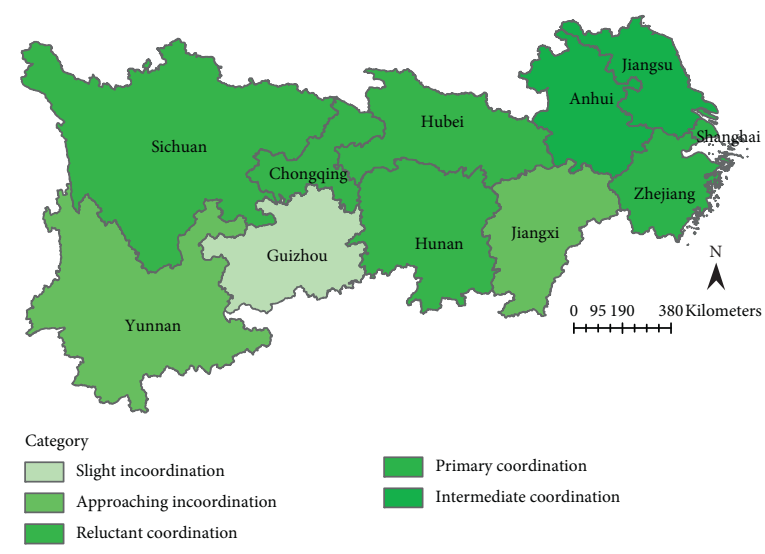

(j)

FIgURE 6: Spatial distributions of the CCD. (a-j) 2009-2018.

Table 7: Prediction of the CCD.

\begin{tabular}{lccccccc}
\hline & & & \multirow{2}{*}{$C$} & \multicolumn{3}{c}{ Prediction } \\
& & & & $P$ & 2019 & 2020 & 2021 \\
\hline ANH & -0.019 & 0.946 & 0.854 & 0.500 & 0.691 & 0.704 & 0.718 \\
CHO & 0.000 & 1.531 & 0.959 & 0.300 & 0.526 & 0.526 & 0.527 \\
GUI & 0.022 & 6.476 & 0.841 & 0.500 & 0.431 & 0.421 & 0.412 \\
HUB & -0.005 & 0.914 & 0.905 & 0.800 & 0.637 & 0.640 & 0.643 \\
HUN & 0.008 & 1.507 & 0.892 & 0.800 & 0.547 & 0.543 & 0.538 \\
JIS & -0.005 & 0.782 & 0.940 & 0.400 & 0.827 & 0.831 & 0.836 \\
JIX & -0.006 & 1.519 & 0.938 & 0.700 & 0.514 & 0.517 & 0.520 \\
SHA & 0.004 & 1.866 & 0.896 & 0.600 & 0.633 & 0.631 & 0.628 \\
SIC & 0.010 & 0.766 & 0.500 & 0.800 & 0.568 & 0.563 & 0.557 \\
YUN & 0.027 & 0.913 & 0.739 & 0.700 & 0.495 & 0.482 & 0.469 \\
ZHE & -0.007 & 0.145 & 0.855 & 0.600 & 0.737 & 0.742 & 0.747 \\
\hline
\end{tabular}

environment; take advantages of technology (blockchains, artificial intelligence, etc.) to stimulate the upgrade of the finance structure and efficiency. (2) Invest more in the air environment governance by utilizing the financial tools effectively and efficiently, for instance, concentrate financial investments on the programs with low air pollutions, and provide more convenient services to air environment friendly industries.

For the regions where the fluctuations are relatively stable without drastic increase or decline, effective endeavors are required to improve the coordination development. (1) Consider the limiting factors of the coordination development, try to achieve breakthroughs, and improve the coordination to the higher status, for instance, introduce local incentive policies to make up for the deficiencies, expand the scale of the finance, optimize financial structures, increase the investment scale in air environment governance, and better control air pollution. (2) Form regional and industrial alliances to achieve coordination development, for example, the southern regions can form strategic alliances with the northern advanced regions; thus, the coordinated cooperation can be realized.

\section{Conclusions}

Taking the regions in the Zone as examples, this study measures and predicts temporally and spatially the coupling coordination status of the finance-air environment system. The conclusions are as follows:

(1) Temporally speaking, the CDD of finance is less fluctuated than that of the air environment. Spatially, the CDDs of the two subsystems have similarities: higher in the east while lower in the west.

(2) Temporally, most regions keep fluctuations of CCD, though the directions and extents of fluctuations vary. Spatially, the distributions of CCD are imbalanced with eastern and northern regions, relatively higher.

(3) The next three years will see the different trends of CCD. Most regions in the coordination range will have benign trends, while those in the transition range will be likely to decline.

There are several highlights:

(1) This paper analyzes the coupling coordination mechanism between finance and air environment and establishes the evaluation index to measure the coupling coordination development between them, which deepens the understanding of the coordination correlations of finance and air environment.

(2) Utilizing the regions of the Zone as examples, this paper measures the CDD and CCD of the finance-air environment system from both temporal and spatial perspectives, which realize the dynamical cross-regional coordination comparisons between finance and air environment.

(3) The countermeasures according to the evolvement and the predictions of the CCD are effective for the related regions and other places with similar situations to take corresponding actions to enhance the coupling coordination status of the finance-air environment system.

\section{Data Availability}

Data are available if requested to the corresponding author. 


\section{Conflicts of Interest}

The authors declare no conflicts of interest.

\section{Authors' Contributions}

Y. G. was responsible for conceptualization, methodology, writing and preparing the original draft, project administration, and funding acquisition and also supervised the work. Y. T. provided software and resources, validated and investigated the work, and was also responsible for formal analysis, data curation, writing the review and editing the paper, and visualization.

\section{Acknowledgments}

This research was funded by Shanghai Municipal Education Commission, grant no. ZZSDJU19012; Shanghai CCP Committee of Education and Health Work, grant no. TZYJ2019-B37; and Shanghai Dianji University, grant no. 19AR20.

\section{References}

[1] Y. Zhu, C. Xie, B. Sun, G. J. Wang, and X. G. Yan, "Predicting China's SME credit risk in supply chain financing by logistic regression, artificial neural network and hybrid models," Sustainability, vol. 8, p. 433, 2016.

[2] Y. Li, T. Chen, and B. Xin, "Optimal financing decisions of two cash-constrained supply chains with complementary products," Sustainability, vol. 8, p. 429, 2016.

[3] Y. Liu, S. J. Wang, Z. X. Qiao, Y. H. Wang, Y. Y. Ding, and C. H. Miao, "Estimating the dynamic effects of socioeconomic development on industrial SO2 emissions in Chinese cities using a DPSIR causal framework," Resources Conservation and Recycling, vol. 150, 2019.

[4] Q. S. Wang, X. L. Yuan, Y. H. Lai, C. Y. Ma, and W. Ren, "Research on interactive coupling mechanism and regularity between urbanization and air environment: a case study in Shandong Province, China," Stochastic Environmental Research and Risk Assessment, vol. 26, pp. 887-898, 2012.

[5] L. J. Han, W. Q. Zhou, W. F. Li, and L. Li, "Impact of urbanization level on urban air quality: a case of fine particles (PM2.5) in Chinese cities," Environmental Pollution, vol. 194, pp. 163-170, 2014.

[6] J. J. Qin, Y. H. Zhao, and L. J. Xia, “Analysis and prediction of the coupling coordination relationship between tourism and air environment: Yangtze River economic zone in China as example," Public Health, vol. 15, p. 750, 2018.

[7] O. Saenz-de-Miera and J. Rossello, "Modeling tourism impacts on air pollution: the case study of PM10 in Mallorca," Tourism Management, vol. 40, pp. 273-281, 2014.

[8] R. M. S. Costa and P. Pavone, "Diachronic biodiversity analysis of a metropolitan area in the Mediterranean region," in International Symposium on Greener Cities for More Efficient Ecosystem Services in a Climate Changing World, G. Pennisi, L. Cremonini, F. Orsini, and G. P. Gianquinto, Eds., vol. 1215pp. 49-52, 2018.

[9] Z. Wang, L. Liang, Z. Sun, and X. Wang, "Spatiotemporal differentiation and the factors influencing urbanization and ecological environment synergistic effects within the BeijingTianjin-Hebei urban agglomeration," Journal of Environmental Management, vol. 243, pp. 227-239, 2019.
[10] X. Hu, "Potential and challenges of carbon finance development in China," in Proceedings of 2015 2nd International Conference on Industrial Economics System and Industrial Security Engineering, Springer, Singapore, pp. 367-373, 2016.

[11] G. Ferrauto, R. M. S. Costa, P. Pavone, and G. L. Cantarella, "Human impact assessment on the Sicilian agroecosystems through the evaluation of melliferous areas," Annals of Botany, vol. 3, pp. 237-244, 2013.

[12] R. M. S. Costa, T. van Andel, P. Pavone, and S. Pulvirenti, "The pre-Linnaean herbarium of Paolo Boccone (1633-1704) kept in Leiden (The Netherlands) and its connections with the imprinted one in Paris," Plant Biosystems, vol. 3, no. 152, pp. 489-500, 2018.

[13] A. Cuspilici, P. Monforte, and M. A. Ragusa, "Study of Saharan dust influence on PM10 measures in Sicily from 2013 to 2015," Ecological Indicators, vol. 76, pp. 297-303, 2017.

[14] P. Wu, H. Cheng, and H. Li, "The effectiveness of environmental policy mix: evidence from the Zhejiang sewage treatment policy," Discrete Dynamics in Nature and Society, vol. 2020, Article ID 6185629, 12 pages, 2020.

[15] Y. Wang and Q. Zhi, "The role of green finance in environmental protection: two aspects of market mechanism and policies," Energy Procedia, vol. 104, pp. 311-316, 2016.

[16] C. Fischer, "Environmental protection for sale: strategic green industrial policy and climate finance," Environmental and Resource Economics, vol. 66, no. 3, pp. 553-575, 2017.

[17] P. Soundarrajan and N. Vivek, "Green finance for sustainable green economic growth in India," Agricultural Economics (Zemédělská ekonomika), vol. 62, pp. 35-44, 2016.

[18] W. J. Liu, F. C. Jiao, L. J. Ren, X. G. Xu, J. C. Wang, and $\mathrm{X}$. Wang, "Coupling coordination relationship between urbanization and air environment security in Jinan City," Journal of Cleaner Production, vol. 204, pp. 1-11, 2018.

[19] L. Ding, W. T. Zhao, Y. L. Huang, S. G. Cheng, and C. Liu, "Research on the coupling coordination relationship between urbanization and air environment: a case study of the area of Wuhan," Air, vol. 6, pp. 1539-1558, 2015.

[20] L. He, D. Zhao, and L. Xia, "Game theoretic analysis of carbon emission abatement in fashion supply chains considering vertical incentives and channel structures," Sustainability, vol. 7, no. 4, pp. 4280-4309, 2015.

[21] P. Naess, J. Xue, H. Stefansdottir, R. Steffansen, and T. Richardson, "Second home mobility, climate impacts and travel modes: can sustainability obstacles be overcome?" Journal of Transport Geography, vol. 79, Article ID 102468, 2019.

[22] X. Li and Y. Li, "Chain-to-chain competition on product sustainability," Journal of Cleaner Production, vol. 112, pp. 2058-2065, 2016.

[23] M. Masi, D. Steven, and G. Janet, "Supply chain configurations in the circular economy: a systematic literature review," Sustainability, vol. 9, no. 9, p. 1602, 2017.

[24] Y. Zhou, M. Bao, X. Chen, and X. Xu, "Co-op advertising and emission reduction cost sharing contracts and coordination in low-carbon supply chain based on fairness concerns," Journal of Cleaner Production, vol. 133, pp. 402-413, 2016.

[25] S. Xiao, S. P. Sethi, M. Liu, and S. Ma, "Coordinating contracts for a financially constrained supply chain,” Omega, vol. 72, pp. 71-86, 2017.

[26] J. Qin, X. Bai, and L. Xia, "Sustainable Trade credit and replenishment policies under the cap-and-trade and carbon tax regulations," Sustainability, vol. 7, no. 12, pp. 16340-16361, 2015.

[27] W. L. Chen, X. J. Huang, Y. H. Liu, and Y. Song, "Does industry integration improve the competitiveness of China's 
electronic information industry? - evidence from the integration of the electronic information industry and finance," Sustainability, vol. 11, p. 2695, 2019.

[28] Y. Fu, W. D. He, and R. Hao, "Comparative analysis of finance competitiveness of regions in China," Journal of Scientific and Industrial Research, vol. 78, pp. 11-14, 2019.

[29] A. P. Kirilenko and S. Stepchenkova, "Tourism research from its inception to present day: subject area, geography, and gender distributions," PLoS One, vol. 13, no. 11, Article ID e0206820, 2018.

[30] W. Wane, J. J. Qiao, J. L. Cheng, Y. N. Sun, and W. C. He, "Research on the impact of economic development of tourism industry based on low carbon mode," International Journal of Low-Carbon Technologies, vol. 14, no. 2, pp. 241-246, 2019.

[31] A. Duro, V. Piccione, M. A. Ragusa, and V. Veneziano, "New enviromentally sensitive patch index- ESPI- for MEDALUS protocol," AIP Conference Proceedings, vol. 1637, pp. 305-312, 2014.

[32] Y. Kameyama, K. Morita, and I. Kubota, "Finance for achieving low-carbon development in Asia: the past, present, and prospects for the future," Journal of Cleaner Production, vol. 128, pp. 201-208, 2016.

[33] T. Latinovic, D. Preradovic, C. R. Barz, A. P. Vadean, and M. Todic, "Big data as the basis for the innovative development strategy of the industry 4.0," IOP Conference Series: Materials Science and Engineering, vol. 477, Article ID 012045, 2019.

[34] M. Purdon, "Opening the black box of carbon finance "additionality": the political economy of carbon finance effectiveness across Tanzania, Uganda, and Moldova," World Development, vol. 74, pp. 462-478, 2015.

[35] C. W. Lee and J. Zhong, "Financing and risk management of renewable energy projects with a hybrid bond," Renewable Energy, vol. 75, pp. 779-787, 2015.

[36] P. Kouvelis and W. Zhao, "Who should finance the supply chain? Impact of credit ratings on supply chain decisions," Manufacturing \& Service Operations Management, vol. 20, no. 1, pp. 19-35, 2018.

[37] M. C. Lozada, "Industry 4.0: the era of digitalization, generation and integration of industrial knowledge," Ingenius (Revista de la Facultad de Ciencia y Tecnología), vol. 21, p. 7, 2019.

[38] S. Tan, J. Yang, J. Y. Yan, C. Lee, H. Hashim, and B. Chen, “A holistic low carbon city indicator framework for sustainable development,” Applied Energy, vol. 185, pp. 1919-1930, 2017.

[39] V. Nitivattananon and S. Srinonil, "Enhancing coastal areas governance for sustainable tourism in the context of urbanization and climate change in eastern Thailand," Advances in Climate Change Research, vol. 10, pp. 47-58, 2019.

[40] Y. Q. Geng, Z. J. Wei, H. Zhang, and M. Mukasar, "Analysis and prediction of the coupling coordination relationship between tourism and air environment: Yangtze River economic zone in China as example," Discrete Dynamics in Nature and Society, vol. 2020, Article ID 1406978, 15 pages, 2020.

[41] Y. G. Zhu, Q. J. Zhu, and Y. T. Zhu, "Modeling, evaluation and analysis of tourism destination competitiveness: a case study of the Yangtze River delta of China," Asia Pacific Journal of Tourism Research, vol. 19, pp. 932-949, 2014.

[42] X. Yu and A. Y. Lo, "Carbon finance and the carbon market in China," Nature Climate Change, vol. 5, no. 1, pp. 15-16, 2015.

[43] M. Y. Wu, Y. G. Wei, P. R. Lam, F. Z. Liu, and Y. Li, "Is urban development ecologically sustainable? Ecological footprint analysis and prediction based on a modified artificial neural network model: a case study of Tianjin in China," Journal of Cleaner Production, vol. 237, Article ID 117795, 2019.

[44] N. Gambetta, A. Paula, H. Victoria, and R. E. Maria, "The financing framework for sustainable development in emerging economies: the case of Uruguay," Sustainability, vol. 11, p. 1059, 2019.

[45] L. Yang, Y. F. Chen, and J. N. Ji, "Cooperation modes of operations and financing in a low-carbon supply chain," Sustainability, vol. 10, p. 821, 2018.

[46] J. J. Qin, Y. H. Zhao, and L. J. Xia, "Carbon emission reduction with capital constraint under greening financing and cost sharing contract," International Journal of Environmental Research and Public Health, vol. 15, p. 750, 2018.

[47] Y. Q. Geng, M. Maimaituerxun, and H. Zhang, "Coupling coordination of water governance and tourism: measurement and prediction," Discrete Dynamics in Nature and Society, vol. 2020, Article ID 3683918, 13 pages, 2020.

[48] D. Cui, X. Chen, Y. L. Xue, R. Li, and W. H. Zeng, "An integrated approach to investigate the relationship of coupling coordination between social economy and water environment on urban scale - a case study of Kunming," Journal of Environmental Management, vol. 234, pp. 189-199, 2019.

[49] K. C. Liao, M. Y. Yue, S. W. Sun et al., "An evaluation of coupling coordination between tourism and finance," Sustainability, vol. 10, no. 7, p. 2320, 2018.

[50] Y. Q. Tan and Y. Q. Geng, "Coupling Coordination Measurement of Environmental Governance: Case of China," Environmental and Ecological Statistics, vol. 27, pp. 1-20, 2020.

[51] N. N. Liu, C. Z. Liu, Y. F. Xia, and B. W. Da, "Examining the coordination between urbanization and eco-environment using coupling and spatial analyses: a case study in China," Ecological Indicators, vol. 93, pp. 1163-1175, 2018.

[52] B. Zeng, H. M. Duan, and Y. F. Zhou, "A new multivariable grey prediction model with structure compatibility," Applied Mathematical Modelling, vol. 75, pp. 385-397, 2019.

[53] Z. Du, Y. G. Hu, and N. A. Buttar, "Analysis of mechanical properties for tea stem using grey relational analysis coupled with multiple linear regression," Scientia Horticulturae, p. 260,2020 . 